\title{
Efeito da adição de butirato de sódio, propionato de cálcio ou monensina sódica no concentrado inicial sobre parâmetros ruminais e de desenvolvimento do rúmen de bezerros leiteiros ${ }^{1}$
}

\section{Lucas Silveira Ferreira ${ }^{2}$, Carla Maris Machado Bittar ${ }^{3}$, Vanessa Pillon dos Santos ${ }^{2}$, Wilson Roberto Soares Mattos ${ }^{3}$, Alexandre Vaz Pires ${ }^{3}$}

\author{
1 Projeto financiado pela FAPESP. \\ 2 Programa de Pós-Graduação em Ciência Animal e Pastagens, Departamento de Zootecnia, USP/ESALQ, Piracicaba, SP. \\ ${ }^{3}$ Departamento de Zootecnia, USP/ESALQ, Piracicaba, SP.
}

RESUMO - O objetivo neste trabalho foi avaliar o efeito da inclusão de butirato de sódio, monensina sódica ou propionato de cálcio no concentrado inicial sobre parâmetros ruminais e de desenvolvimento do trato digestório superior de bezerros leiteiros. Quinze bezerros holandeses recém-nascidos foram fistulados no rúmen e alojados em baias individuais até a décima semana de vida, com livre acesso a água, alimentados com leite (4 L/dia), em duas refeições, e concentrado à vontade contendo butirato de sódio $(0,15 \%)$, monensina sódica $(30 \mathrm{ppm})$ ou propionato de cálcio $(0,15 \%)$. A partir da quarta semana de vida dos animais, antes e 2 horas após a alimentação da manhã, foram realizadas colheitas semanais de fluido ruminal para determinação do pH, da concentração de ácidos graxos de cadeia curta (AGCC) e N-amoniacal. Ao completar 10 semanas, os animais foram abatidos para avaliação do crescimento do trato digestório superior. O pH ruminal apresentou diferenças, tanto entre horários quanto entre os aditivos utilizados no concentrado inicial. As concentrações de AGCC totais, bem como de cada ácido graxo, não foram afetadas pelos aditivos. Entretanto, o horário de colheita teve efeito sobre todos os parâmetros, exceto a concentração molar de ácido acético. O peso total do trato digestório superior, assim como o peso médio de cada compartimento e a capacidade máxima do retículo-rúmen, não foram afetados pelos aditivos fornecidos no concentrado. Também não foram observados efeitos dos aditivos sobre a altura, a largura e o número de papilas do epitélio ruminal. A inclusão desses aditivos no concentrado inicial não afeta os parâmetros ruminais ou de desenvolvimento do trato digestório de bezerros em aleitamento.

Palavras-chave: aditivos, desaleitamento precoce, desenvolvimento ruminal, ionóforos, papilas ruminais, retículo-rúmen

\section{Effect of inclusion of sodium butyrate, calcium propionate or sodium monensin in the starter feed on ruminal parameters and forestomach development in dairy calves}

\begin{abstract}
The objective of this study was the evaluation of the inclusion of calcium propionate, sodium butyrate and sodium monensin in the starter concentrate on ruminal parameters and forestomach development in dairy calves. Fifteen newborn Holstein calves were rumen cannulated and housed in individual stalls until ten weeks old, with free access to water, fed 4 liters of milk per day, split in two meals, and starter concentrate ad libitum containing sodium butyrate (0.15\%), sodium monensin $(30 \mathrm{ppm})$ or calcium propionate $(0.15 \%)$. Starting at the fourth week of life, before and 2 hours after the morning feeding, ruminal fluid samples were taken weekly to determine the $\mathrm{pH}$, short-chain fatty acids and ammonia-N. After 10 weeks, the animals were slaughtered to assess the forestomach growth. The rumen $\mathrm{pH}$ was affected by sampling time and the additives used in the starter concentrate. The total short-chain fatty acids concentration and each fatty acid concentration, were was not affected by the additives. However, except for molar concentration of acetic acid, all rumen fermentation parameters were affected by sampling time. The total forestomach weight and the average weight of each compartment and the maximum reticulum-rumen capacity were not affected by additives supplied in the starter concentrate. No significant effects of the additives were observed on the height, width and number of papillae of the ruminal epithelium. The inclusion of these additives in starter concentrate had no effect on most of the ruminal parameters and forestomach development in suckling calves.
\end{abstract}

Key Words: additives, early weaning, ionophores, reticulum-rumen, ruminal development, ruminal papillae 


\section{Introdução}

Ao nascer, os bovinos apresentam o abomaso muito desenvolvido e o retículo-rúmen com desenvolvimento rudimentar e pouco funcional. Durante o desenvolvimento dos animais recém-nascidos à condição de ruminante funcional, ocorre uma série de mudanças anatômicas e fisiológicas do aparelho digestório (Beharka et al., 1998). Além disso, embora esse desenvolvimento seja inato, a idade tem pouca influência no processo de maturação do epitélio ruminal e no desenvolvimento de papilas ruminais, estruturas importantes para a absorção dos produtos finais resultantes da fermentação microbiana.

Resultados de trabalhos desenvolvidos nas décadas de 50 e 60 identificaram a presença dos ácidos graxos de cadeia curta (AGCC), principalmente butírico e propiônico como os fatores específicos que envolvem o desenvolvimento do epitélio ruminal (Warner et al., 1956; Tamate et al., 1962). Com base no conhecimento dos efeitos positivos dos ácidos butírico e propiônico no desenvolvimento e na maturação do epitélio ruminal de bezerros durante a fase de transição pré-ruminante para ruminante funcional, a adição de butirato ou propionato, na forma de seus respectivos sais, pode ser uma alternativa interessante para essa categoria animal.

Resultados de diversos trabalhos mostram melhorias no controle da coccidiose e no desempenho de bezerros em aleitamento consumindo ionóforos como a monensina e a lasalocida (Stromberg et al.,1986; Anderson et al., 1988; Sinks et al., 1992). Entretanto, em outros trabalhos não foram observadas vantagens no uso de ionóforos para bezerros em aleitamento quando o objetivo é alcançar melhores desempenhos e desenvolvimento ruminal mais precoce por meio de alterações nos padrões de fermentação ruminal (Quigley et al., 1992; Nussio et al., 2002; Nussio et al., 2003a).

Dessa forma, apesar de resultados com o uso de monensina não serem sempre consistentes, dados de literatura mostram melhores ganhos de peso e conversão alimentar de bezerros recebendo ionóforos na dieta. Entretanto, o modo de ação de ionóforos em bezerros em aleitamento e com o rúmen em desenvolvimento ainda é pouco estudado.

O objetivo neste estudo foi avaliar o efeito da inclusão de butirato de sódio, monensina sódica ou propionato de cálcio no concentrado inicial sobre parâmetros ruminais e de desenvolvimento do rúmen de bezerros leiteiros.

\section{Material e Métodos}

Foram utilizados 15 bezerros holandeses machos em delineamento experimental do tipo blocos ao acaso. Os animais foram adquiridos de fazendas comerciais da região e transportados entre 1 e 7 dias de vida para o Departamento de Zootecnia da Escola Superior de Agricultura "Luiz de Queiroz”, Piracicaba, São Paulo, onde o experimento foi realizado.

Após o nascimento, os animais foram separados da mãe, receberam 2 litros de colostro em duas refeições diárias, até o segundo dia de vida ou conforme protocolo da fazenda de origem. Decorrido esse período, os animais passaram a receber leite (4 L/dia, divididos em duas refeições, às $7 \mathrm{~h}$ e às $18 \mathrm{~h}$ ) e tiveram livre acesso a água e concentrado inicial.

Entre 3 e 7 dias após o nascimento, os animais foram submetidos a cirurgia para colocação de cânulas no rúmen e alojados em baias individuais $(1,5 \times 3,0 \mathrm{~m})$, com piso concretado, além de cocho e bebedouro individuais. Após a cirurgia, os animais foram divididos entre os blocos considerando o peso ao nascer e a data de nascimento e distribuídos conforme aditivo incluído no concentrado inicial: butirato de sódio $(0,15 \%)$; monensina sódica (30 ppm); ou propionato de cálcio (0,15\%).

O concentrado comercial farelado (Guabi Nutrição Animal ${ }^{\circledR}$ ), composto por milho, farelo de soja, farelo de trigo e mistura mineral, foi fornecido toda manhã, à vontade, até que o animal atingisse o consumo de $2 \mathrm{~kg} / \mathrm{dia}$, pesando-se a sobra do dia anterior, de forma a se obter o consumo diário de concentrado. Um único concentrado inicial foi formulado de acordo com as recomendações do NRC (2001) para atender às exigências desses animais contendo no mínimo 18\% de proteína bruta (PB) e 70\% de nutrientes digestíveis totais (NDT). Os aditivos foram misturados ao concentrado utilizando-se um misturador de rações tipo "Y" com capacidade máxima para $20 \mathrm{~kg}$.

Amostras dos concentrados fornecidos foram colhidas para determinação de matéria seca (MS) a $105{ }^{\circ} \mathrm{C}$ e extrato etéreo (EE) de acordo com Campos et al. (2002); proteína bruta (PB), por combustão, conforme método de Dumas, utilizando-se o analisador de nitrogênio LECO ${ }^{\circledR}$, modelo FP-528; e fibra insolúvel em detergente neutro (FDN) e fibra insolúvel em detergente ácido (FDA), pelo método descrito por Van Soest et al. (1991). Os valores de nutrientes digestíveis totais (NDT) foram calculados de acordo com as equações propostas por Kearl (1982) (Tabela 1).

Tabela 1 - Composição química do concentrado experimental

\begin{tabular}{lr}
\hline Composição química & $\%$ MS \\
\hline Matéria seca & 90,42 \\
Proteína bruta & 20,60 \\
Extrato etéreo & 2,59 \\
Fibra em detergente neutro & 19,35 \\
Fibra em detergente ácido & 9,23 \\
Nutrientes digestíveis totais & 70,37 \\
\hline
\end{tabular}


A partir da quarta semana de vida dos animais, foram realizadas colheitas de fluido ruminal, a cada 7 dias, antes e duas horas após a alimentação da manhã até a décima semana de vida. As amostras (aproximadamente $50 \mathrm{~mL}$ ) foram colhidas de todas as porções do rúmen, com auxílio de um tubo plástico. A determinação de $\mathrm{pH}$ foi realizada imediatamente após a amostragem, em potenciômetro digital (DMPH-2, DIGIMED), e a amostra armazenada a $-10^{\circ} \mathrm{C}$ para posterior determinação das concentrações de ácidos graxos de cadeia curta e nitrogênio amoniacal.

A determinação dos ácidos graxos de cadeia curta (AGCC) foi realizada no Laboratório de Bromatologia do Departamento de Zootecnia da USP/ESALQ, onde as amostras foram analisadas em cromatógrafo líquido-gasoso (Hewlett Packard 5890, Series II GC), equipado com integrador (Hewlett Packard 3396, Series II Integrator) e injetor automático (Hewlett Packard 6890, Series Injector), conforme descrito por Campos et al. (2002). A determinação de $\mathrm{N}-\mathrm{NH}_{3}$ foi realizada conforme método de Chaney \& Marbach (1962) adaptado para leitura em placas de microtítulo em aparelho Microplate Reader BIO RAD com filtro para absorbância de $550 \mathrm{~nm}$.

Ao completar 10 semanas de vida, os animais foram abatidos por meio de atordoamento e sangria, com o corte da jugular. Os animais tiveram sua cavidade abdominal aberta e os quatro compartimentos foram retirados livres de tecido adiposo omental. O conteúdo do trato digestório superior foi retirado por lavagens com água. Os compartimentos divididos em retículo-rúmen, omaso e abomaso. A capacidade máxima do retículo-rúmen foi medida com auxílio de amarrações na saída desse compartimento, que foi cheio com água até sua máxima capacidade e o volume medido em proveta. Depois de retirado o excesso de água dos tecidos, foram tomadas medidas de peso do retículo-rúmen, do omaso, do abomaso e dos quatro compartimentos em conjunto.
Amostras do saco ventral do rúmen foram retiradas com auxílio de bisturi, preservadas em solução de formaldeído $10 \%$ e posteriormente avaliadas quanto à altura e largura de papilas, além de número de papilas por $\mathrm{cm}^{2}$, por meio de microscópio estereoscópico provido de escala. Foram avaliadas três amostras por animal e mensuradas pelo menos 10 papilas de cada amostra para determinação de altura e largura médias, conforme proposto por Lesmeister et al. (2004).

Os dados de consumo de MS e de parâmetros ruminais ( $\mathrm{pH}, \mathrm{N}$-amoniacal e ácidos graxos de cadeia curta) foram analisados como medidas repetidas no tempo pelo PROC MIXED do pacote SAS (1991), utilizando-se o peso ao nascer como covariável. As medidas morformétricas do trato digestório superior, assim como as medidas relativas ao desenvolvimento do rúmen (papilas) foram analisadas pelo PROC GLM do programa estatístico SAS (1991).

\section{Resultados e Discussão}

A utilização dos aditivos no concentrado não ocasionou diferenças $(\mathrm{P}>0,05)$ no consumo de concentrado (g MS/dia) durante o período experimental (Tabela 2). Como previsto, houve efeito da idade no consumo de concentrado $(\mathrm{P}<0,0001)$, que aumentou de forma linear com os aumentos no consumo até a sexta semana de vida dos animais, entretanto, após esse período, a adição de monensina ou propionato de cálcio no concentrado ocasionou reduções no consumo, comportamento atípico para animais nesse período de vida. Esse efeito também foi observado por outros autores em animais alimentados com rações contendo monensina, provavelmente em virtude do desenvolvimento do rúmen e do efeito desse ionóforo na fermentação e na taxa de passagem do alimento (Mcguffey et al., 2001).

Embora o consumo não tenha apresentado variações significativas entre os aditivos (Figura 1), com a adição de butirato de sódio ao concentrado, observou-se tendência

Tabela 2 - Consumo de concentrado e características de fermentação ruminal

\begin{tabular}{|c|c|c|c|c|c|c|c|}
\hline \multirow[t]{2}{*}{ Parâmetro } & \multicolumn{3}{|c|}{ Aditivo } & \multirow[t]{2}{*}{ Erro-padrão } & \multicolumn{3}{|c|}{ Valor de $\mathrm{P}$} \\
\hline & $\begin{array}{l}\text { Butirato } \\
\text { de sódio } \\
(0,15 \%)\end{array}$ & $\begin{array}{l}\text { Monensina } \\
\text { sódica } \\
(30 \mathrm{ppm})\end{array}$ & $\begin{array}{c}\text { Propionato } \\
\text { de cálcio } \\
(0,15 \%)\end{array}$ & & Aditivo & Idade & Aditivo $\times$ Idade \\
\hline Consumo de concentrado, g MS/dia & 440,2 & 351,4 & 380,7 & 122,8 & 0,87 & $<0,0001$ & 0,52 \\
\hline $\mathrm{pH}$ & $5,90 \mathrm{~b}$ & $6,30 \mathrm{a}$ & $5,91 b$ & 0,10 & 0,03 & 0,05 & 0,34 \\
\hline AGCC total, mM & 79,58 & 58,83 & 62,15 & 11,26 & 0,40 & 0,25 & 0,18 \\
\hline Acético, mM & 42,88 & 30,89 & 32,56 & 5,64 & 0,29 & 0,08 & 0,12 \\
\hline Propiônico, mM & 26,19 & 19,53 & 20,21 & 4,49 & 0,53 & 0,45 & 0,83 \\
\hline Butírico, mM & 7,13 & 5,21 & 6,19 & 1,10 & 0,48 & 0,19 & 0,56 \\
\hline Acetato:propionato & 2,28 & 2,08 & 2,19 & 0,24 & 0,84 & 0,007 & 0,81 \\
\hline N-amoniacal, mg/dL & 16,48 & 15,77 & 12,96 & 1,82 & 0,34 & $<0,0001$ & 0,04 \\
\hline
\end{tabular}

Médias com letras minúsculas na mesma linha diferem $(\mathrm{P}<0,05)$ pelo teste $\mathrm{t}$. 


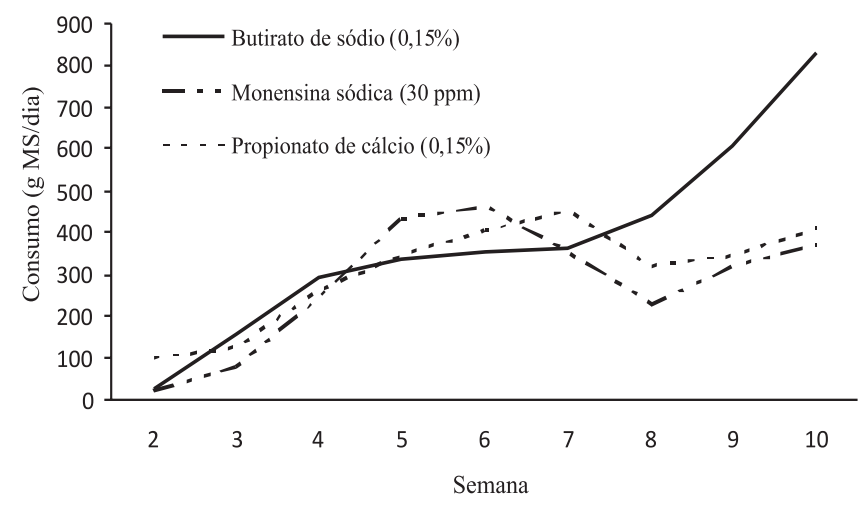

Figura 1 - Consumo em bezerros leiteiros alimentados com concentrado contendo aditivos até a décima semana de idade.

de aumento no consumo pelos animais desde o início do experimento.

Os dados indicam que, principalmente com a adição de monensina sódica e propionato de cálcio no concentrado, o desaleitamento não prejudicaria o desempenho animal somente se essa adição fosse realizada após a décima semana de vida, quando o consumo atingiria entre 700 e 800 g de matéria original de concentrado durante três dias consecutivos (Quigley, 1996). Entretanto, o estresse cirúrgico para a implantação de cânulas teve efeito marcante no consumo de concentrado.

Os aditivos tiveram efeito $(\mathrm{P}<0,05)$ no $\mathrm{pH}$ ruminal médio, que apresentou maiores valores nos animais consumindo o concentrado com monensina (Tabela 2). Outros autores observaram valores de $\mathrm{pH}$ ruminal semelhantes em bezerros em aleitamento alimentados com concentrados com diferentes processamentos físicos (Greenwood et al., 1997) ou alimentados com grãos processados com ou sem inclusão de monensina (Nussio et al., 2003b), com valores numericamente superiores para os animais recebendo monensina.

Quigley et al. (1992) observaram redução no $\mathrm{pH}$ ruminal de bezerros sob suplementação com lasalocida, outro ionóforo, antes ou após o desaleitamento. Segundo esses autores, esse efeito se deve à inibição do crescimento de bactérias ruminais durante as primeiras semanas de vida dos animais consumindo esses produtos, assim como observado por Anderson et al. (1987).

Também foram observados efeitos significativos $(\mathrm{P}<0,05)$ da idade (semanas) nos valores de $\mathrm{pH}$, entretanto a interação aditivo $\times$ idade não foi significativa (Tabela 2). Nussio et al. (2003b) verificaram redução do pH ruminal com o avanço da idade em bezerros canulados, assim como Beharka et al. (1998), que, em bezerros consumindo concentrados de diferentes formas físicas, observaram aumento somente após a décima semana de vida dos animais, principalmente em decorrência do aumento no consumo de forragem. Por outro lado, Vazquez-Anon et al. (1993) observaram maiores valores de $\mathrm{pH}$ com o avanço da idade em bezerros alimentados com dieta contendo 85\% de concentrado.

A concentração total de ácidos graxos de cadeia curta (AGCC) não foi alterada ( $\mathrm{P}>0,05)$ pelos aditivos (Tabela 2 ). Esperava-se que as concentrações totais desses ácidos graxos no rúmen dos animais aumentassem de forma crescente $(\mathrm{P}>0,05)$ com a idade, no entanto isso não ocorreu. Eram esperados aumentos na concentração total de ácidos graxos de cadeia curta, principalmente em decorrência do fornecimento dos sais dos principais ácidos graxos com o concentrado inicial. Entretanto, é possível que o baixo consumo de concentrado tenha prejudicado a avaliação desse parâmetro.

Outros autores observaram tendência de aumento nas concentrações de AGCC com o avanço da idade de bezerros em aleitamento (Greenwood et al., 1997; Beharka et al., 1998; Kristensen et al., 2007). Coverdale et al. (2004) encontraram valores crescentes nas concentrações totais de AGCC ruminais em bezerros alimentados com dietas contendo diferentes formas físicas e níveis de inclusão de forragem. Os valores encontrados neste estudo foram menores que os observados em estudos com bezerros leiteiros com o rúmen desenvolvido, que geralmente apresentam ao desaleitamento concentrações ruminais de AGCC próximas àquelas de animais adultos (120 a 160 mM; Bergman, 1990).

Valores de concentração total de AGCC próximos aos deste estudo foram relatados por Khan et al. (2007) no rúmen de bezerros desaleitados aos 49 dias de vida. Suarez et al. (2006) constataram aumento na concentração total de AGCC com o avanço da idade em bezerros consumindo concentrado com diversas fontes energéticas em comparação a animais consumindo grandes quantidades de leite, o que reflete melhor desenvolvimento do rúmen de animais em resposta ao consumo de concentrado. Por outro lado, Nussio et al. (2003b) encontraram baixas concentrações de AGCC totais no fluido ruminal de bezerros canulados consumindo ou não monensina e relacionaram esse resultado ao baixo consumo pelos animais.

Não houve efeito dos aditivos na concentração molar de ácido acético $(\mathrm{P}>0,05)$, no entanto houve efeito da idade do animal $(\mathrm{P}=0,08)$ e interação aditivo $\times$ idade $(\mathrm{P}=0,12)$, uma vez que, nos animais alimentados com o concentrado contendo monensina as maiores concen-trações molares desse ácido ocorreram a partir da sexta semana. Outros autores também não observaram diferença na concentração 
de ácido acético no fluido ruminal de bezerros alimentados com concentrado contendo ou não monensina (Nussio et al., 2003b) ou lasalocida (Quigley et al., 1992). Coverdale et al. (2004) observaram tendência de aumento nas concentrações de ácido acético com o aumento no fornecimento de forragem, característico do tipo de fermentação desse alimento no rúmen.

Também não foram observadas diferenças entre os aditivos para as concentrações molares de ácido propiônico $(\mathrm{P}>0,05)$. A adição de propionato de cálcio ou monensina não teve o efeito esperado na concentração desse ácido graxo de cadeia curta no rúmen, cujos valores foram de 19,53 e 20,21 mM nos animais alimentados com os concentrados contendo, respectivamente, monensina e propionato de cálcio. Entretanto, os baixos níveis de consumo entre esses animais podem ter prejudicado os resultados, uma vez que a quantidade de monensina e de propionato de cálcio que chegava ao rúmen proveniente do concentrado foi baixa.

De acordo com McGuffey et al. (2001), o uso de ionóforos como a monensina ou a lasalocida é realizado visando à maior produção de ácido propiônico no rúmen de animais adultos. Entretanto, pesquisas com bezerros em aleitamento têm comprovado que a adição de ionóforos como a lasalocida ou monensina não tem efeito na concentração molar de ácido propiônico (Quigley et al., 1992; Nussio et al., 2003b).

Esperava-se que as concentrações de propionato no rúmen aumentassem com a idade dos animais, principalmente em decorrência do aumento no consumo de concentrado. Entretanto, embora a idade não tenha afetado $(\mathrm{P}>0,05)$ essa variável, as concentrações ruminais de propionato reduziram exatamente após a sexta semana, comportamento provocado principalmente pela redução no consumo nesse período. Vazquez-Anon et al. (1993) não observaram variação na concentração de propionato no rúmen com o avanço da idade em bezerros consumindo dieta contendo $85 \%$ de concentrado. Da mesma forma, Suarez et al. (2006) não verificaram diferenças nas concentrações molares de propionato com o avanço da idade, porém constataram que as maiores produções desse ácido no rúmen ocorreram nos bezerros alimentados com a dieta à base de amido como fonte energética.

As concentrações molares de ácido butírico não diferiram $(\mathrm{P}>0,05)$ entre os aditivos, apesar dos valores numericamente superiores obtidos com a adição de butirato de sódio no concentrado inicial (Tabela 2). É possível que, com adequado consumo de concentrado, pudessem ocorrer maiores concentrações desse ácido graxo de cadeia curta em comparação aos outros aditivos no concentrado inicial. Não existem na literatura dados obtidos com o fornecimento de butirato de sódio via concentrado para bezerros, o que dificulta a análise de seu potencial como aditivo para animais em aleitamento. O baixo consumo pode ter comprometido os resultados esperados, de maiores concentrações molares de ácido butírico no rúmen, ácido graxo de maior importância no desenvolvimento de papilas ruminais (Lane \& Jesse, 1997).

As concentrações de ácido butírico foram inferiores ao esperado para animais com 10 semanas de idade, quando a concentração no fluido ruminal é superior a $10 \mathrm{mM}$ (Beharka et al., 1998; Coverdale et al., 2004), assim como os observados para os outros ácidos graxos de cadeia curta. Como previsto, a adição de monensina resultou em menor produção de butirato no rúmen, assim como relatado por Quigley et al. (1992), que observaram menor produção de ácido butírico em bezerros sob suplementação com lasalocida no período após o desaleitamento. Segundo esses autores, a redução na produção de butirato e acetato com o uso de ionóforos reflete aumento na produção de propionato, entretanto esse efeito não foi observado neste trabalho.

A relação acetato:propionato não foi afetada $(\mathrm{P}>0,05)$ pelos aditivos (Tabela 2). A relação acetato:propionato aumentou numericamente $(\mathrm{P}<0,05)$ com o avanço na idade dos animais. Quigley et al. (1992) observaram menores valores na relação acetato:propionato em bezerros consumindo concentrado com lasalocida durante o período de aleitamento, o que reflete a alta produção de propionato e baixa de acetato, comum em animais consumindo dietas concentradas. Por outro lado, Nussio et al. (2003b) também não observaram efeito da adição de monensina no concentrado inicial na relação acetato:propionato.

A concentração de $\mathrm{N}$-amoniacal não foi influenciada pelos aditivos fornecidos no concentrado inicial $(\mathrm{P}>0,05)$, mas houve efeitos da idade $(\mathrm{P}<0,0001)$ e interação aditivo $\times$ idade $(\mathrm{P}<0,05)$ (Figura 2$)$. Os valores médios são comparáveis aos observados por Suarez et al. (2006) e Nussio et al. (2003b), entretanto a concentração de $\mathrm{N}$-amoniacal no rúmen diferiu da observada em diversos trabalhos, nos quais houve redução nas concentrações com o avanço da idade dos animais, principalmente pelo aumento na utilização pela população bacteriana ou pelo início da absorção pela parede ruminal (Beharka et al., 1998). A evolução atípica dos dados sugere menor proliferação de bactérias no ambiente ruminal, principalmente em virtude do baixo consumo, resultando em menor incorporação de $\mathrm{N}$-amoniacal à proteína microbiana e aumentando sua concentração no fluido ruminal. Entretanto, de acordo com Quigley et al. (1992), a elevada concentração ruminal de amônia também pode estar relacionada ao aumento no consumo e na fração proteica degradada no rúmen. 


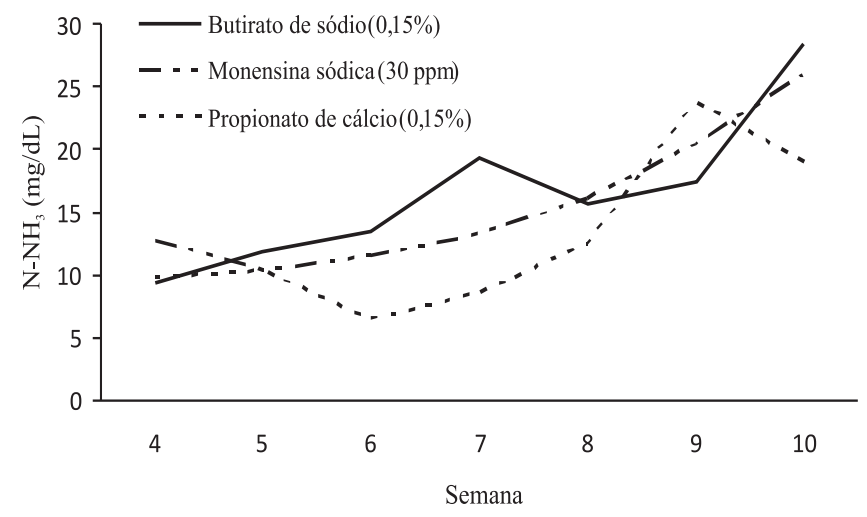

Figura 2 - Concentrações ruminais de $\mathrm{N}$-amoniacal em bezerros leiteiros alimentados com concentrado contendo aditivos até a décima semana de idade.

Os aditivos tiveram efeito $(\mathrm{P}<0,05)$ nos valores de $\mathrm{pH}$, que diminuíram com o tempo de fornecimento do alimento, entretanto não foram observadas diferenças em mesmo horário de colheita (Tabela 3). Para todos os aditivos, os menores valores foram obtidos 2 horas após a alimentação, assim como observado por Anderson et al. (1988) e Nussio et al. (2003b).

Coelho et al. (2000) também observaram menores valores de $\mathrm{pH}$ ruminal até 3 horas após a alimentação da manhã, provavelmente ocasionados pela rápida fermentação de grãos consumidos neste período. Vazquez-Anon et al. (1993) relataram efeito semelhante, com maior redução 2 horas após o consumo, comprovando a rápida fermentação ruminal e consequente produção de ácidos graxos de cadeia curta. Esse comportamento está fortemente relacionado à fase de transição do animal de pré-ruminante para ruminante funcional, uma vez que o desenvolvimento do tecido epitelial ruminal está associado ao consumo de concentrado e à consequente produção de ácidos graxos de cadeia curta (Ochoa et al., 1994).

Embora a concentração ruminal de $\mathrm{N}$-amoniacal não tenha diferido entre aditivos (Tabela 2), foram observadas diferenças $(\mathrm{P}<0,05)$ entres os horários de fornecimento do alimento (Tabela 3). Os resultados indicaram redução na concentração 2 horas após o consumo, comportamento semelhante ao observado no trabalho de Nussio et al. (2003b). Vazquez-Anon et al. (1993) observaram aumento nas concentrações de amônia ruminal em bezerros 2 horas após o aleitamento, com redução após este período, na quarta e oitava semana de vida dos animais. Também observaram redução na concentração de amônia 2 horas após o aleitamento durante a segunda semana e atribuíram esse resultado ao reduzido consumo de concentrado nesta fase da vida do animal.

As concentrações molares dos ácidos propiônico, butírico, bem como a concentração molar total de AGCC, também apresentaram diferenças entre os horários de colheita $(\mathrm{P}<0,05)$ : os maiores valores ocorreram 2 horas após a alimentação da manhã. Entretanto, a concentração molar do ácido acético não diferiu entre os horários, provavelmente em virtude do tipo de alimento consumido pelos animais, que pode reduzir a produção desse ácido durante a fermentação ruminal. Os resultados são comparáveis aos encontrados por Nussio et al. (2003b), de aumento nas concentrações desses ácidos graxos de cadeia curta após o fornecimento de concentrado, o que sugere rápida fermentação ruminal desse tipo de alimento.

Tabela 3 - Características de fermentação ruminal em cada horário de colheita

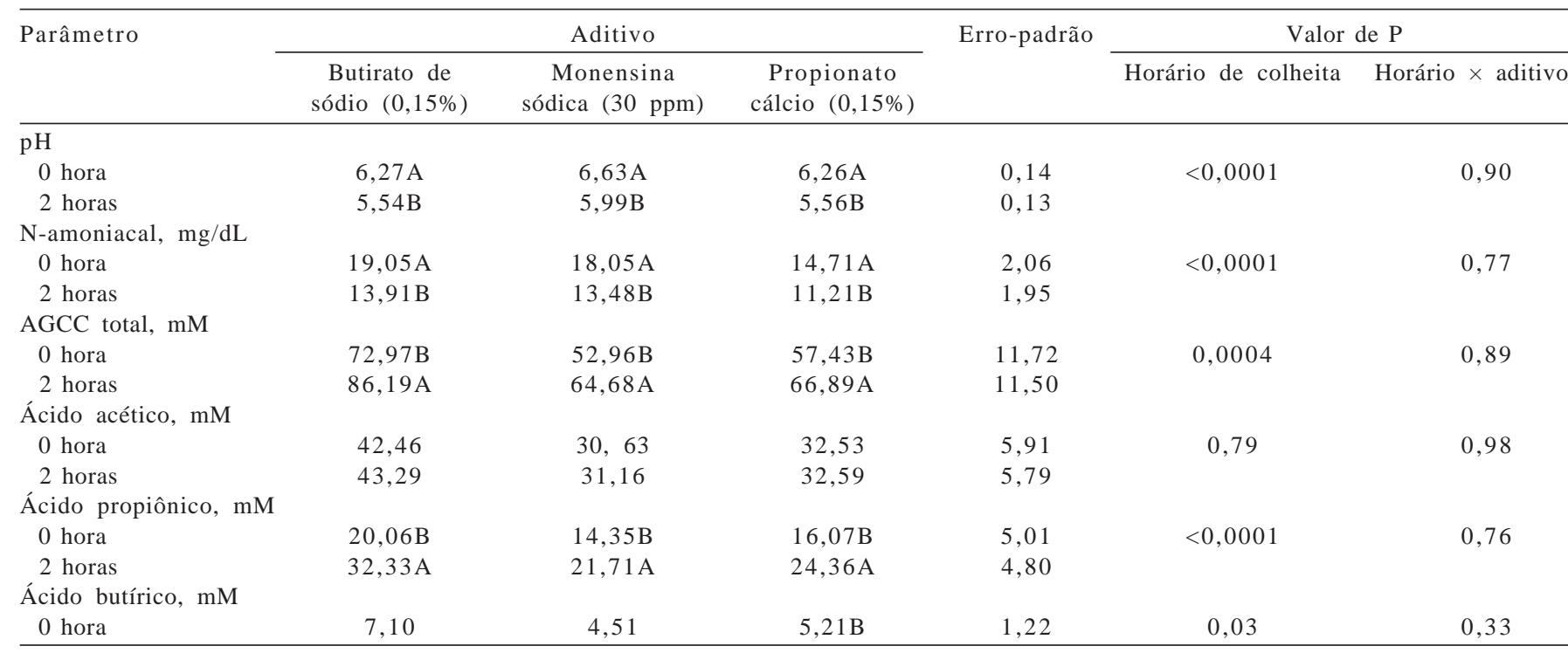

Médias com letras maiúsculas na mesma coluna diferem $(\mathrm{P}<0,05)$ pelo teste $\mathrm{t}$. 
Segundo esses autores, o pico de produção ocorreu 2 horas após o consumo e reduziu após esse período, principalmente pela absorção e pelo metabolismo desses ácidos graxos de cadeia curta pelo epitélio ruminal.

Não foram observados efeitos $(\mathrm{P}>0,05)$ dos aditivos no peso do trato digestório superior total no momento do abate (Tabela 4). Também não foram observadas diferenças nos pesos médios de cada compartimento nem em porcentagem do trato total. Os valores observados são superiores aos observados por Nussio et al. (2003b) em bezerros alimentados com ração contendo ou não monensina, quando expressos em gramas. Entretanto, são semelhantes, quando expressos em \% do PV, provavelmente devido ao maior porte dos animais utilizados neste trabalho.

Tamate et al. (1962) observaram maiores valores em porcentagem do trato total para os compartimentos do trato digestório superior de bezerros consumindo diferentes dietas e com infusão intrarruminal de sais de ácidos graxos. Na oitava semana de vida, foram observadas proporções de retículo-rúmen próximas às encontradas em animais adultos (80\%). Avaliando o desenvolvimento do trato digestório superior de bezerros desaleitados precocemente, Carvalho et al. (2003) observaram aumentos no tamanho e alterações nas proporções dos compartimentos com o avanço da idade dos animais, com pesos de retículorúmen em bezerros com 50 dias de idade maiores que os encontradas neste estudo.

Entretanto, Greenwood et al. (1997) também não observaram diferenças significativas no peso do retículorúmen em bezerros alimentados com dietas com diferentes níveis de processamento físico, assim como Beharka et al. (1998) em bezerros alimentados com concentrados de diferentes tamanhos de partícula.
Neste trabalho, a capacidade do retículo-rúmen também não foi afetada pelos aditivos, fator relacionado diretamente à idade do animal e principalmente ao consumo de alimento volumoso. Suarez et al. (2006) observaram maior peso do rúmen de bezerros consumindo dietas com maior proporção de FDN ou pectina quando comparados a animais consumindo dietas ricas em amido. Estes resultados mostram a relação entre maior proporção de fibra na dieta e desenvolvimento físico do rúmen, porém influenciam pouco no desenvolvimento do epitélio ruminal e de sua capacidade absortiva.

Bunting et al. (2000) forneceram propionato de cálcio $(6,4 \%)$ ou de cromo $(0,5 \mathrm{mg} / \mathrm{kg})$ via substituto de leite e observaram tendência nos animais recebendo propionato de cálcio de apresentarem maior crescimento do retículorúmen no momento do abate (6 semanas). Huber (1969) demonstrou que o peso do retículo-rúmen, quando expresso em \% do trato total, alcançou valores próximos a $65 \%$ na sexta semana de vida e que esse valor não se altera com o avanço da idade.

O desenvolvimento do epitélio ruminal avaliado com medidas de altura, largura e número de papilas por $\mathrm{cm}^{2}$ não foi afetado pelos aditivos no concentrado inicial $(\mathrm{P}>0,05)$ (Tabela 4). Os valores observados para altura de papilas são similares aos apresentados por Beharka et al. (1998) em bezerros alimentados com ração com diferentes formas físicas, assim como os encontrados por Hill et al. (2005) com bezerros alimentados com diferentes dietas.

Os resultados de número de papilas por $\mathrm{cm}^{2}$ observados neste estudo foram bastante inferiores ao observados por Beharka et al.(1998), provavelmente devido ao baixo consumo de concentrado, o que pode ter comprometido os resultados esperados com a adição de butirato de sódio ou propionato de cálcio ao concentrado inicial.

Tabela 4 - Medidas morfométricas e de desenvolvimento do trato digestório superior e do epitélio ruminal de bezerros leiteiros alimentados com concentrado contendo aditivos

\begin{tabular}{|c|c|c|c|c|c|}
\hline \multirow[b]{2}{*}{ Parâmetro } & \multicolumn{3}{|c|}{ Aditivo } & \multirow[t]{2}{*}{ Erro-padrão } & \multirow[t]{2}{*}{ Valor de $\mathrm{P}$} \\
\hline & $\begin{array}{c}\text { Butirato de } \\
\text { sódio }(0,15 \%)\end{array}$ & $\begin{array}{c}\text { Monensina } \\
\text { sódica (30 ppm) }\end{array}$ & $\begin{array}{l}\text { Propionato de } \\
\text { cálcio }(0,15 \%)\end{array}$ & & \\
\hline \multicolumn{6}{|c|}{ Trato digestório superior } \\
\hline Trato total, g & 979,1 & 1023,1 & 1054,8 & 46,96 & 0,67 \\
\hline Retículo-rúmen, g & 614,6 & 666,2 & 709,2 & 49,95 & 0,54 \\
\hline$\%$ Trato total & 61,4 & 62,4 & 66,3 & 2,19 & 0,35 \\
\hline Omaso, g & 124,5 & 121,0 & 116,5 & 12,68 & 0,92 \\
\hline$\%$ Trato total & 12,7 & 12,3 & 11,0 & 1,08 & 0,59 \\
\hline Abomaso, g & 239,9 & 234,9 & 229,1 & 7,30 & 0,67 \\
\hline$\%$ Trato total & 25,9 & 25,3 & 22,7 & 1,72 & 0,46 \\
\hline \multicolumn{6}{|c|}{ Epitélio ruminal } \\
\hline Altura de papilas, mm & 3,73 & 2,69 & 3,22 & 1,53 & 0,87 \\
\hline Largura de papilas, $\mathrm{mm}$ & 1,20 & 0,88 & 1,25 & 0,44 & 0,82 \\
\hline Número por $\mathrm{cm}^{2}$ & 121,6 & 141,6 & 121,6 & 27,18 & 0,83 \\
\hline
\end{tabular}


Os resultados de contagem de papilas por $\mathrm{cm}^{2}$ geralmente apresentam grande variabilidade entre os dados (Lesmeister et al., 2004) e diminuem consideravelmente a possibilidade de detecção de diferenças entre os aditivos, principalmente por se tratar de um procedimento passível de erros. Coelho et al. (2000) observaram alturas de papilas de amostras do saco ventral do rúmen de bezerros desaleitados aos 30 dias e abatidos aos 90 dias de idade, de aproximadamente $2 \mathrm{~mm}$.

Embora trabalhos in vitro (Sakata \& Tamate, 1979) comprovem benefícios na administração de sais de ácidos graxos no desenvolvimento e na maturação do epitélio ruminal, a falta de estabelecimento de uma dosagem adequada prejudica a obtenção de melhores respostas in vivo. De acordo com o estudo de Baldwin e McLeod (2000) com células isoladas do epitélio ruminal de carneiros e infusão direta de sais de ácidos graxos, o butirato e o propionato foram identificados como os ácidos graxos de cadeia curta absorvidos mais prontamente pelo epitélio ruminal. A adição de soluções fracas desses ácidos graxos no retículo-rúmen de bezerros alimentados com leite (sem oferta de dieta sólida) ocasiona maiores mudanças na taxa de crescimento do tecido papilar desses compartimentos e maior desenvolvimento da capacidade absortiva (Sutton et al., 1963). O fornecimento de sais butirato de sódio e propionato de sódio através de cânula ruminal resulta em maior desenvolvimento papilar em bezerros em aleitamento (Sander et al., 1959).

Por outro lado, Tamate et al. (1962) observaram tendência de aumento na altura e no número de papilas com o avanço da idade de bezerros, apesar de não terem encontrado efeitos benéficos da administração de sais de ácidos graxos diretamente no rúmen. Costa (2003) observou resposta semelhante, com alterações no crescimento normal de papilas do saco ventral do rúmen de bezerros submetidos à infusão de butirato no rúmen, e concluiu que a administração do ácido graxo de cadeia curta foi incapaz de promover as respostas esperadas, de aumento em tamanho e área das papilas ruminais. Zitnan et al. (2005) observaram maior desenvolvimento do epitélio ruminal em bezerros consumindo dietas que promovessem maior concentração molar de ácido propiônico. Neste trabalho, a concentração molar de ácido butírico no fluido ruminal não diferiu entre os aditivos, embora o desenvolvimento do epitélio tenha sido diferente, o que indica que o propionato tem maior importância no processo.

\section{Conclusões}

A inclusão de butirato de sódio, monensina sódica ou propionato de cálcio no concentrado inicial de bezerros leiteiros não afeta a maioria dos parâmetros de fermentação ruminal ou de desenvolvimento do trato digestório superior.

\section{Literatura Citada}

ANDERSON, K.L.; NAGARAJA, T.G.; MORRIL, J.L. et al. Ruminal microbial development in conventionally or early weaned calves. Journal of Animal Science, v.64, p.1215-1226, 1987.

ANDERSON, K.L.; NAGARAJA, T.G.; MORRILL, J.L. et al. Performance and ruminal changes of early-weaned calves fed lasalocid. Journal of Animal Science, v.66, p.806-813, 1988.

BALDWIN, R.L.; MCLEOD, K.R. Effects of diet forage:concentrate ratio and metabolizable energy intake on isolated rumen epithelial cell metabolism in vitro. Journal of Animal Science, v.78, p.771-783, 2000.

BEHARKA, A.A.; NAGARAJA, T.G.; MORRILL, G.A. et al. Effects of form of the diet on anatomical, microbial, and fermentative development of the rumen of neonatal calves. Journal of Dairy Science, v.81, p.1946-1955, 1998.

BERGMAN, E.N. Energy contributions of volatile fatty acids from the gastrointestinal tract in various species. Physiological Reviews, v.70, p.567-590, 1990.

BUNTING, L.D.; TARIFA, T.A.; CROCHET, B.T. et al. Effects of dietary of chromium propionate and calcium propionate on glucose disposal and gastrointestinal development. Journal of Dairy Science, v.83, p.2491-2498, 2000.

CAMPOS, F.P.; NUSSIO, C.M.B.; NUSSIO, L.G. Métodos de análises de alimentos. Piracicaba: Fundação de Estudos Agrários Luiz de Queiroz, 2002. 135p.

CARVALHO, P.A.; SANCHEZ, L.M.B.; VIEGAS, J. et al. Desenvolvimento de estômago de bezerros Holandeses desaleitados precocemente. Revista Brasileira de Zootecnia, v.32, n.6, p.1461-1468, 2003.

CHANEY A.L.; MARBACH, E.P. Modified reagents for determination of urea and ammonia. Clinical Chemistry, v.8, p.130-132, 1962.

COELHO, S.G.; SATURNINO, H.M.; CALIARI, M.V. et al.pH ruminal, tamanho e área das papilas do saco ventral até os 90 dias de idade de bezerros desmamados aos 30 dias e alimentados com ou sem volumoso até os 60 dias. In: REUNIÃO ANUAL DA SOCIEDADE BRASILEIRA DE ZOOTECNIA, 37., 2000 , Viçosa, MG. Anais... Viçosa, MG: Sociedade Brasileira de Zootecnia, 2000. (CD-ROM).

COSTA, S.F. Alterações morfológicas induzidas por butirato, propionato e lactato sobre a mucosa ruminal e epiderme de bezerros. 2003. 123f. Tese (Doutorado em Zootecnia) Universidade Federal de Lavras, Lavras, 2003.

COVERDALE, J.A.; TYLER H. D; QUIGLEY, J. D. III. et al. Effect of various levels of forage and form of diet on rumen development and growth in calves. Journal of Dairy Science, v.87, p.2554-2562, 2004.

GREENWOOD, R.H.; MORRILL, J.L.; TITGEMEYER, E.C. et al. A new method of measuring diet abrasion and its effect on the development of the forestomach. Journal of Dairy Science, v.80, p.2534-2541, 1997.

HILL, S.R.; HOPKINS, B.A.; DAVIDSON, S. et al. Technical Note: Technique for dissection and analysis of the rumen in young calves. Journal of Dairy Science, v.88, p.324-326, 2005.

HUBER, J.T. Development of the digestive and metabolic apparatus of the calf. Journal of Dairy Science, v.52, p.1303-1315, 1969.

KEARL, L.C. Nutrient requirement of ruminants in developing countries. Logan: International Feedstuffs Institute, Utah State University, 1982. 381p.

KHAN, M.A.; LEE, H.J.; LEE, W.S. et al. Structural growth, rumen development, and metabolic and immune responses of Holstein male calves fed milk through step-down and conventional methods. Journal of Dairy Science, v.90, p.3376-3387, 2007. 
KRISTENSEN, N.B.; SEHESTED, J.; JENSEN S.K. et al. Effect of milk allowance on concentrate intake, ruminal environment, and ruminal development in milk-fed Holstein calves. Journal of Dairy Science, v.90, p.4346-4355, 2007.

LANE, M.A.; JESSE, B.W. Effect of volatile fatty acid infusion on development of rumen epithelium in neonatal sheep. Journal of Dairy Science, v.80, p.740-746, 1997.

LESMEISTER, K.E; TOZER, P.R.; HEINRICHS, A.J. Development and analysis of a rumen tissue sampling procedure. Journal of Dairy Science, v.87, p.1336-1344, 2004.

McGUFFEY, R.K.; RICHARDSON, L.F.; WILKINSON, J.I.D. Ionophores for dairy cattle: current status and future outlook. Journal of Dairy Science, v.84, p.194-203, 2001.

NATIONAL RESEARCH COUNCIL - NRC. Nutrient requirement in dairy cattle. 7.ed. Washington, D.C.: National Academy of Science, 2001. 381p.

NUSSIO, C.M.B.; HUBER, J.T.; NUSSIO, L.G. Decoquinate, lasalocid and monensin for starter feeds and the performance of Holstein calves to 20 weeks of age. Scientia Agricola, v.59, n.3, p.421-426, 2002.

NUSSIO, C.M.B.; SANTOS, F.A.P.; ZOPOLLATTO, M. et al. Processamento de milho (floculado vs. laminado a vapor) e adição de monensina para bezerras leiteiras, pré e pós-desmama precoce. Revista Brasileira de Zootecnia, v.32, n.1, p.229-239, 2003a.

NUSSIO, C.M.B.; SANTOS, F.A.P.; ZOPOLLATTO, M. et al. Parâmetros de fermentação e medidas morfométricas dos compartimentos ruminais de bezerros leiteiros suplementados com milho processado (Floculado vs. Laminado a vapor) e monensina. Revista Brasileira de Zootecnia, v.32, n.4, p.1021-1031, 2003b.

OCHOA, S.M.; NEIVA, R.S.; GIRÃO, L.C.F. et al. Desenvolvimento ruminal e papilar em bezerros mestiços (Holandês-Zebu). Ciência e Prática, v.18, n.3, p.320-325, 1994.

QUIGLEY III, J.D. Feeding prior to weaning. In: CALVES, HEIFERS AND DAIRY PROFITABILITY NATIONAL CONFERENCE. 1996, Harrisburg. Proceedings... Harrisburg: Northeast regional agricultural engineering service cooperative extension, 1996. p.245-255.

QUIGLEY III, J.D.; BOEHMS, I.; STEEN, T.M. et al. Effects of lasalocid on selected ruminal and blood metabolites in young calves Journal of Dairy Science, v.75, p.2235-2241, 1992.
SAKATA, T.; TAMATE, H. Rumen epithelium cell proliferation accelerated by propionate and acetate. Journal of Dairy Science, v.62, p.49-52, 1979.

SANDER, E.G.; WARNER, R.G.; HARRISON H.N. et al. The stimulatory effect of sodium butyrate and sodium propionate on the development of rumen mucosa in the young calf. Journal of Dairy Science, v.42, p.1600-1605, 1959.

SINKS, G.D.; QUIGLEY III, J.D.; REINEMEYER, C.R. Effects of lasalocid on coccidial infection and growth in young dairy calves. Journal of American Veterinary Medicine Association, v.200, p.1947, 1992.

STATISTICAL ANALYSIS SYSTEM - SAS. SAS users guide: Statistics. Version 5. Cary: SAS Institute, 1991. 1028p.

STROMBERG, B.E.; SCHLOTTAUER, J.C.; HAMANN, K.J. et al. Experimental bovine coccidiosis: control with monensin Veterinary Parasitology, v.22, p.135-140, 1986.

SUAREZ, B.J.; VAN REENEN, C.G.; BELDMAN, G. et al. Effects of supplementing concentrates differing in carbohydrate composition in veal calf diets: I. animal performance and rumen fermentation characteristics. Journal of Dairy Science, v.89, p.4365-4375, 2006.

SUTTON, J.D.; McGILLIARD, A.D.; RICHARD, M. et al. Funcional development of rumen mucosa. II. Metabolic activity. Journal of Dairy Science, v.46, 530-537, 1963.

TAMATE, H.; MCGILLIARD, A.D.; JACOBSON, N.L. et al. Effect of various dietaries on the anatomical development of the stomach in the calf. Journal of Dairy Science, v.45, p.408-420, 1962.

VAN SOEST, P.J.; ROBERTSON, J.B.; LEWIS, B.A. Methods for dietary fiber neutral detergent fiber, and non-starch polysaccharides in relation to animal nutrition. Journal of Dairy Science, v.74, p.3583-3597, 1991.

VAZQUEZ-ANON, M.; HEINRICHS, A.J.; ALDRICH, J.M. et al. Postweaning age effects on rumen fermentation end-products and digesta kinetics in calves weaned at 5 weeks of age. Journal of Dairy Science, v.76, p.2742-2748, 1993.

WARNER, R.G.; FLATT, W.P.; LOOSLI, J.K. Dietary factors influencing the development of the ruminant stomach. Journal of Agricultural and Food Chemistry, v.4, p.788-792, 1956

ZITNAN, R.; KUHLA, S.; SANFTLEBEN, P. et al. Diet induced ruminal papillae development in neonatal calves not correlating with rumen butyrate. Veterinary Medicine, v.11, p.472-479, 2005. 